\title{
El Debate sobre la CRIMINALIDAd Desde el Diario de OcCidente por Serafín Quiteño. El Salvador, 1939
}

\author{
Óscar Meléndez*
}

E n enero de 1939 en el Diario de Occidente (medio impreso editado en el departamento de Santa Ana) se publicaron once artículos de opinión sobre las causas y los responsables de la criminalidad en El Salvador. La pregunta con la que se tituló la serie de artículos aclaraba su contenido: "Los pistoleros consentidos. ¿Quiénes son los verdaderos culpables de la criminalidad en nuestro país?" Quien emitía su opinión, sobre lo que se consideraba un verdadero problema social, ${ }^{1}$ era el director del Diario, el periodista, escritor, y también funcionario público, Serafín Quiteño. El propósito de estas líneas es presentar uno de los artículos publicados por este escritor salvadoreño, así como el contexto y el debate suscitado en torno a sus ideas sobre la criminalidad.

El Diario de Occidente fue fundado en 1910 por Rosendo Díaz Galiano en el departamento de Santa Ana (López, 1964: 384). El Diario se ubicó dentro de la prensa moderna: variedad de imágenes, realce a las noticias en extensas notas, y un amplio espacio para los hechos criminales de El Salvador, pero sobre todo del occidente del país. Era un periódico que se asemejaba a los que se publicaban en San Salvador, y era similar a los periódicos mexicanos y argentinos que se comenzaron a publicar desde finales del siglo XIX (Speckman, 2007; Caimari, 2004 y 2007).
Serafín Quiteño fungió como director del Diario de Occidente desde 1935 hasta julio de 1939; su ascenso a la dirección ocurrió luego de que Carlos Manuel Flores (director de ese mismo medio impreso) junto con Mariano Morán (director del Diario de Santa Ana) fueron expulsados hacia Nicaragua por el dictador Maximiliano Hernández Martínez (López, 1964: 311).²

Quiteño perteneció a la élite intelectual de la época: se desempeñó como poeta, trabajó para diversos periódicos, e incluso fue funcionario de la secretaría privada de la Presidencia de la República en 1935. Compartió ideas literarias y políticas con personajes como, por ejemplo, Salarrué, Claudia Lars, Alfonso Rochac, Alberto Guerra Trigueros y José Mejía Vides. Perteneció al círculo intelectual Grupo Masferer, que apoyó la política cultural del martinato (Lara, 2011).

Su posición como intelectual -y no obstante su simpatía con el régimen - le permitió lanzar críticas a las políticas diseñadas para contener la criminalidad. En los editoriales publicados en el Diario enumeró las causas que a su juicio fomentaban y permitían la criminalidad en El Salvador. Las leyes poco rigurosas, el dinero con el que se podía comprar abogados y testigos, la tolerancia de la sociedad —ola nula "sanción social"-, el ineficiente papel del jurado popular, y la descomposición moral de las personas eran, según

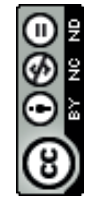

Recibido: 1 de octubre de 2018

\footnotetext{
* Óscar Meléndez. Investigador del Grupo de trabajo sobre historia de la violencia en El Salvador y Jefe de Acervos Históricos de la Biblioteca Florentino Idoate, S.J. de la Universidad Centroamericana José Simeón Cañas. Correo electrónico: omelendez@gmail.com. ORCID: https:// orcid.org/0000-0001-6147-3133.
} 
Quiteño, algunos de los grandes catalizadores del crimen. Tanto realce tuvieron las opiniones del director del Diario de Occidente que sus artículos incluso fueron reproducidos en El Diario de Hoy, un medio impreso de la capital salvadoreña que había sido fundado en 1936 y cuyo tiraje, a solo unos años de existencia, alcanzaba los cincuenta mil al día (López, 1964).

Lo que motivó a Quiteño a emitir esas opiniones fue un homicidio que ocurrió la noche del 14 de enero de 1939 en Santa Ana. Esa noche, Carlos Deras, un campesino que observaba una función de un circo rural, fue asesinado a tiros. Deras se había instalado en la copa de unos árboles que servían de carpa al circo. El circo se había ubicado en la finca La Montañita, propiedad de una poderosa familia cafetalera de Santa Ana de apellido Interiano (Acosta, 2014). En los días posteriores, la prensa occidental y la de San Salvador se dedicó a dar cobertura al caso y al proceso judicial seguido contra un miembro de la familia Interiano, Ernesto Interiano, catalogado como el principal sospechoso pues, según varios testigos, siempre disparaba al aire al salir de la finca.

"El crimen del circo", como lo denominó la prensa, fue un caso que generó agitación en los periódicos del occidente y de San Salvador. En su mayoría, las expresiones que exigían castigo para Interiano provenían de los mismos medios impresos —principalmente del Diario de Hoy, La Prensa Gráfica, el Diario de Occidente y el Diario de Santa Ana-, por considerar el homicidio una tragedia social que debía sancionarse con severidad. En sus denuncias subrayaban que ese tipo de manifestaciones de violencia eran parte de la vida cotidiana. Así lo determinó, por ejemplo, el Diario de Occidente en la edición del 16 de enero de 1939:

En la finca la "Montañita", de esta jurisdicción, se registró antier noche uno de esos dramas rurales que a pesar de no ser frecuentes, no dejan de presentarse allá de tarde en tarde. Esta vez no se trata de una lucha leal entre campesinos. No se trata de la reyerta a filo de corvo y a impulsos de una pasión de esas que si no justifican la violencia, al menos la explican en cierta forma (Diario de Occidente, 16 de enero, p. 5).
Finalmente, luego de los debates judiciales y de las solicitudes por parte de la defensa para archivar el proceso, el "crimen del circo" fue cerrado el 24 de agosto de 1939, con el decreto de libertad para Interiano, después de haber estado recluido en la penitenciaría occidental. No obstante, Serafín Quiteño aprovechó el homicidio cometido en Santa Ana para debatir sobre quiénes eran los criminales salvadoreños y cómo debía castigárseles.

El lenguaje de Quiteño no estuvo desprovisto de los conceptos que se habían esgrimido desde el siglo XIX para explicar la criminalidad y para castigar al criminal, desde las corrientes del positivismo criminológico, tanto de la llamada escuela antropológica (italiana) como de la sociológica (francesa). La escuela de antropología criminal se enfocó en el organismo del criminal, y la sociológica le otorgó más preeminencia a factores ambientales, culturales o sociales.

Los conceptos de Serafín Quiteño demostraban que sus ideas en torno al criminal y al castigo eran eclécticas entre lo que postulaban ambas escuelas criminológicas. Así, definía al criminal como un ser anormal, producto de deformaciones heredadas, un ser impulsivo al que no sólo debían aplicarse penas severas, sino que también se le debía separar de la sociedad en tanto que representaba la parte enferma de ella.

Quiteño también apelaba al concepto de defensa o sanción social basándose en el criterio de la peligrosidad del delincuente y de su animadversión a la sociedad. Era por ello que culpaba al jurado popular, a los abogados, a los jueces, e incluso a los periodistas, por no defender con más ahínco a la parte buena o sana de la sociedad. Todo lo anterior concuerda con lo que habían expuesto Lombroso, Ferri, Garofalo y los franceses (Baratta, 2004; Pavarini, 2002; Speckman, 2007).

Todas estas ideas plasmadas por Quiteño habían sido debatidas por los intelectuales de Iberoamérica desde finales del siglo XIX. Según Rosa del Olmo (1999), el interés por la criminología en la región, y concretamente por la escuela positivista italiana, surgió en tres países a finales del siglo XIX: Argentina, Brasil y México. A través de las cátedras de derecho penal estas ideas se comenzaron a difundir desde 1887 en la Universidad 
de Buenos Aires, y desde 1889 en México. Esto dio paso a que en estos países se desarrollara un extenso trabajo editorial, mediante la publicación de libros y revistas en los que se transcribieron o contemplaron las ideas positivistas, y comenzaron a surgir asociaciones de juristas y de "criminólogos" o "científicos", con el propósito de discutir temas relacionados con el crimen y el criminal. Como lo demuestran, por ejemplo, Caimari (2004) y Speckman (2007), en Argentina y en México, respectivamente, hubo intensos debates entre los intelectuales sobre cómo adaptar a sus realidades concretas estas teorías criminológicas.

En El Salvador, Herrera sostiene que, al aproximarse el siglo XX, fueron posicionándose con más preeminencia los postulados del positivismo criminológico entre los intelectuales salvadoreños. Si bien es cierto, hubo un debate sobre las causas del delito y las penas y se contemplaron ciertas críticas al positivismo, "la acogida de esta escuela, en el país, se hizo inminente" (Herrera, 2007: 218). Aun así, el positivismo no estuvo exento de críticas al iniciar la nueva centuria, y las discusiones se prolongaron en torno a la educación de los reos, a la utilización de las penitenciarías como laboratorios y a la solución de la criminalidad desde las teorías de la "defensa social".

En relación con lo planteado por Herrera, Oliva (2010), sostiene que en El Salvador desde finales del siglo XIX,

el higienismo social pareciera haberse constituido en un dispositivo con el cual se buscó construir una realidad social que partiendo de una visión biologicista, clasificó e identificó a los grupos de población considerados peligrosos, y sobre los cuales aplicó las medidas pertinentes para su disciplinamiento, coerción y eventual exterminio (Oliva, 2010: 19).

Según Oliva (2010), se asimilaron los conceptos del positivismo de Augusto Comte, de algunas expresiones del darwinismo social de Herbert Spencer y de la antropología criminal de Lombroso. Los postulados de estos autores fueron utilizados en El Salvador decimonónico para inventar la "ciudadanía" y las "clases peligrosas", es decir, "con el higienismo social —sostiene
Oliva - se buscó crear las condiciones ideológicas y materiales para permitir que el nuevo orden económico y político liberal se instaurara en El Salvador de finales del siglo XIX" (Oliva, 2010: 82).

Volviendo a los artículos publicados por Quiteño, también es importante señalar que éstos tuvieron eco en otros escritores o periodistas coetáneos a él. El director del Diario de Occidente aseguraba que el problema de la criminalidad en El Salvador debía discutirse ampliamente; para ello publicó una encuesta que fue titulada "Sobre las causas de la criminalidad y las fallas de la sanción social". Dos ejemplos muestran cómo la discusión colocada por Quiteño fue recibida por otros que, como él, emitían su opinión sobre el crimen y la criminalidad desde la prensa, y cómo sus ideas estaban impregnadas de los postulados del positivismo criminológico.

El primer ejemplo es una carta que escribió Ricardo Augusto Lima en la que mostró su adhesión a la campaña de Quiteño. La carta de Lima fue publicada primero en el Diario Latino, y el l de febrero de 1939 en el Diario de Occidente. Lima se dedicó al periodismo y estuvo muy ligado a los círculos intelectuales de Quiteño. Fue corresponsal del Diario de Occidente, y entre otros cargos fungió como encargado de la sección judicial del Diario Latino, y el de director del Diario Oficial desde 1944 hasta 1948 (López, 1964). Lima afirmó que era necesaria una "política profiláctica" que acabara con los cimientos del crimen: una "limpieza social" que debía basarse en un principio de autoridad, ejemplar y severo, contra quienes no podía "dejar de sentir aspiraciones dolosas o dejarse impulsar por el sendero inclinado de la irreflexión".

El otro artículo fue publicado en ElDiario de Hoy el 29 de enero de 1939, y fue reproducido el día 31 del mismo mes y año en el Diario de Occidente. Ese artículo lo escribió Salvador Cañas, periodista también cercano a los círculos intelectuales de Quiteño. Sus escritos aparecieron en el periódico Patria, de Alberto Masferrer, y en otros medios impresos de carácter cultural (López, 1964).

Salvador Cañas manifestó que lo escrito por Quiteño denotaba su "valentía y nobleza" y, al igual que Ricardo Augusto Lima, consideraba necesario 
emprender programas de carácter higiénico por medio del desarrollo de proyectos de "depuración social". No obstante, también culpaba al sistema de administración de justicia y a las bases éticas y económicas de la sociedad. Para Cañas era a través de la escuela y la familia como debía conducirse la labor de "saneamiento moral" de la sociedad, pero subrayaba que recaía mayor responsabilidad en el seno familiar, pues era ahí donde se debía enseñar a los menores a responder a la altura de los principios éticos expuestos en la escuela. Finalmente, exigió que los casos de delincuencia que preocupaban a la sociedad debían ser examinados en relación con el ambiente que los provocaba. En cuanto a los castigos, no se limitó a expresar que debía recluirse a los delincuentes, sostuvo que se tenían que investigar las "causas biológicas, psicológicas, educativas y económicas" que los producía.

El documento que se presenta a continuación es el cuarto artículo que publicó Serafín Quiteño. En él se muestra una parte de sus ideas en torno a los criminales, y también se observa cómo sus conceptos estuvieron relacionados con las teorías del positivismo criminológico, tanto en su vertiente italiana como francesa. Quiteño asume en este artículo que hay dos tipos de criminales: primero, los criminales de los sectores populares - a los que él llama "bajos fondos" o "subsuelo social" - y, segundo, los provenientes de los grupos dominantes de la sociedad - generalmente individuos con poder y dinero para comprar armas, testigos, jurados, abogados o jueces-. Los primeros poseen "taras orgánicas" pero, al no garantizárseles los medios para superarlas - como educación, por ejemplo-, se convierten en "animales salvajes sedientos de sangre" a los que hay que "encerrar" o eventualmente matar. Los segundos, a los que también denomina "pistoleros consentidos", que tienen los medios para comprar a los que aplican la ley o imparten justicia, y que cometen crímenes por motivos distintos al padecimiento de deficiencias orgánicas, deben ser, según Quiteño, separados de la sociedad. Al final lanza sus críticas contra quienes se encargan de administrar justicia.
Como puede observarse, la admisión de estas ideas punitivas no sólo es privativa de quienes hacen la ley o la aplican, sino también de otros actores que, desde otros estrados, emiten opiniones y contribuyen a la creación del rostro del criminal. Estos saberes profanos - en tanto que son producidos por quienes no son sus especialistas-, coadyuvan a configurar entramados discursivos hegemónicos sobre quiénes son los criminales y cómo deben ser castigados. Por tanto, también son tribunales en los que no se discute y aplica la ley, sino que están constituidos por la opinión pública.

Este y los demás artículos publicados por Quiteño se encuentran en las ediciones del Diario de Occidente que se resguardan en la hemeroteca especializada del Museo Nacional de Antropología de El Salvador (MUNA). Esta hemeroteca contiene, además, una cantidad importante de otros periódicos salvadoreños del siglo XX. Es un espacio de consulta obligatoria para quienes investigan el siglo XX salvadoreño, pues resguarda ediciones de periódicos que no están disponibles en otros centros de documentación, archivos o hemerotecas. Así, contiene fuentes que son útiles para responder a una agenda de trabajo sobre una historia de la violencia, comprendida en su larga duración y en los procesos de formación del Estado.

\section{Notas}

' Sólo en 1939, de acuerdo con las estadísticas oficiales, se habían reportado 844 muertes violentas en el país. La cantidad de defunciones por violencia fueron realmente alarmantes durante la década de 1930. Sin contar las de 1932 - pues hasta la fecha no se han encontrado registros oficiales de la matanza-, la cantidad de muertes se aproximaba a las mil por año (Meléndez, 2015: 51-81).

${ }^{2}$ En 1939 el general Maximiliano Hernández Martínez fue nombrado por tercera vez presidente de la República. En la Constitución, promulgada el 20 de enero, se estableció que esa decisión se tomaba "excepcionalmente, y por exigirlo así los intereses nacionales"; no obstante, la medida dictatorial del general se repetiría años más tarde, en 1944, pero fue derrocado por un paro cívico militar (Turcios, 2015: 88-89). 


\section{Referencias}

Acosta Rodríguez, Antonio (2014). Los orígenes de la burguesía de El Salvador. El control sobre el café y el Estado. 1848-1890. Sevilla: Taller de Estudios e Investigaciones Andino-Amazónicos-Universidad de Barcelona, Instituto de Estudios sobre América LatinaUniversidad de Sevilla, Aconcagua Libros.

Baratta, Alessandro (2004). Criminología crítica y crítica del derecho penal: introducción a la sociología jurídico-penal. Buenos Aires: Siglo XXI Editores.

Caimari, Lila (2004). Apenas un delincuente: crimen, castigo y cultura en la Argentina, 1880-1955. Buenos Aires: Siglo XXI Editores.

Caimari, Lila (comp.) (2007). La ley de los profanos: delito, justicia y cultura en Buenos Aires (1870-1940). Buenos Aires: Fondo de Cultura Económica.

Del Olmo, Rosa (1999). América Latina y su criminología. México: Siglo XXI Editores.

Herrera Mena, Sajid Alfredo (2007) “'No que muera, sino que se arrepienta el criminal y viva'. El debate sobre el trabajo penitenciario en los impresos salvadoreños, 1880-1900". En Sajid Alfredo Herrera Mena y Ana Margarita Gómez (eds.), Los rostros de la violencia: Guatemalay El Salvador.Siglos XVIIIy XIX. San Salvador: UCA Editores, pp. 189-223.

Lara Martínez, Rafael (2011). Política de la cultura del martinato. San Salvador: Editorial Universidad Don Bosco.
López Vallecillos, Ítalo (1964). El periodismo en El Salvador. San Salvador: Editorial Universitaria.

Meléndez, Óscar (2015). “En ese acto habría saciado su venganza'. Homicidio, justicia y práctica judicial durante el martinato (1932-1944)". En Óscar Meléndez y Adrian Bergman (eds.), Violencia en tiempos de paz: conflictividad y criminalización en El Salvador. San Salvador: Dirección Nacional de Investigaciones en Cultura y Arte, Secretaría de Cultura de la Presidencia de El Salvador, pp. 5l-81.

Oliva Mancia, Mario Daniel (2010). Ciudadanía e higienismo social en El Salvador, 1880-1932. Tesis de Doctor en Filosofía Iberoamericana. Universidad Centroamericana José Simeón Cañas, San Salvador, El Salvador.

Pavarini, Massimo (2002). Control y dominación: teorías criminológicas burguesas y proyecto hegemónico. Buenos Aires: Siglo XXI Editores.

Speckman, Elisa (2007). Crimen y castigo: legislación penal, interpretaciones de la criminalidad y administración de justicia (Ciudad de México, 1872-1910). México: El Colegio de México-Centro de Estudios Históricos, Universidad Nacional Autónoma de México-Instituto de Investigaciones Históricas.

Turcios, Roberto (2015). "La vida política". En Carlos Gregorio López Bernal (coord.), El Salvador. Historia Contemporánea, 1808-2010. San Salvador: Fundación Mapfre y Editorial Universitaria, Universidad de El Salvador, pp. 53-127. 


\section{Diario de Occidente. De información y variedades \\ Viernes, 20 de enero de 1939, p. 5}

\section{LOS PISTOLEROS CONSENTIDOS}

\section{¿Quiénes son los verdaderos culpables de la criminalidad en nuestro país?}

- IV -

El criminal de los bajos fondos, sea cual sea la magnitud de sus delitos, siempre será compadecido a la luz de la comprensión humana. Generalmente se trata de bestezuelas irresponsables, con quienes la vida ha sido cruel y despiadada. Surgidos y criados en las capas ínfimas de la sociedad, no tuvieron las oportunidades que brinda la educación. Sufrieron desde niños las influencias nefastas del mal ejemplo, los rigores del hambre, los mil flagelos envilecedores de la miseria.

Productos tarados por la herencia y abandonados a sus propios impulsos desde la más tierna infancia, es lo probable que al correr del tiempo se revelen como auténticos inadaptados sociales. Las aristas agrias que no fueron desbastadas con el tiempo; los instintos bajos que acabaron de relajarse al choque de realidades duras; la ferocidad exacerbada por el resentimiento, el odio, el desamor; las pasiones sueltas que la sociedad no se encargó de amortiguar o de trascender, necesariamente habrán de convertirse en actores de disolución y de crimen.

Cuando un criminal de estos cobra cuerpo en la fiera sedienta de sangre y de exterminio, ya sus actos, sus reacciones, su modo especial de considerar los valores respetados y establecidos, han venido incubándose lentamente, determinándose en una serie de causas que residen fuera de él mismo. Claro es que la sociedad, al encontrarse ante la evidencia de un animal bravío, no se detiene a considerar los orígenes del fenómeno. Se defiende, sencillamente. Y para defenderse es que ha hecho construir penitenciarías, instituir tribunales de justicia, elaborar leyes, etc.

No es el caso discutir en estas líneas si serían más eficaces las escuelas que las cárceles; la obra lenta pero segura de la redención espiritual en cada individuo, que la pena de muerte; el oficio del amor humano en forma de refugios infantiles, misiones de cultura, combate de las taras orgánicas en la población humilde, y mil actividades más en calidad cooperación social, que la persecución del crimen, en sí mismo.

No. No es ese el tema de este artículo, aun cuando muy bien puede servirnos para uno próximo. Lo que pretendemos ahora es establecer diferencia del criminal extraído de los estratos del subsuelo social, cuyos actos infunden piedad y compasión, aunque por ellos haya necesidad de enjaularlo como a fiera peligrosa, y el pistolero consentido, que practica el homicidio como un deporte y sobre eso tiene la complicidad de su dinero, de las leyes, del compadrazgo, de toda urdimbre de intereses y fuerzas en que descansa el egoísmo colectivo.

No puede haber punto de comparación entre uno y otro. Ya ayer lo decíamos. El primero es una criatura que va lealmente por la calle de en medio. El segundo es un infame y sórdido que gusta las sensaciones del delito, y se sustrae a todos sus riesgos. El primero actúa con la misma despreocupación de las alimañas del campo, más al mismo tiempo se somete a los rigores de la intemperie, de la persecución social, y en no raros casos de la anulación total y la muerte. El segundo es tan criminal como aquel, pero a cada hecho delictuoso tomo pasaje al extranjero como cualquier turista; pone su dinero en marcha para que la justicia de los hombres lo absuelva; y regresa al cabo después de divertirse a lo grande, para pasear su insolencia en los mismos sitios por donde poco antes le estaban maldiciendo.

Es imposible la comparación entre uno y otro. El primero se juega entero en todos los actos de su existencia y tiene, por lo mismo, la oportunidad de que el dolor y la experiencia, como esmeriles de la justicia divina, vayan 
afinando los filos ásperos de su alma, diluyendo la sombra que le impide VER y COMPRENDER, abriéndose posibilidades dormidas hacia el bien.

El segundo es una criatura irredenta, por lo mismo que no tiene oportunidad de sentir en carne propia la responsabilidad de sus faltas; porque un falso amor y una estúpida apreciación de las realidades, se confabulan para justificarle y ponerle a salvo.

Además, un pistolero consentido, de esos que en nuestro país no han tenido otros menesteres que gastarse el dinero en francachelas y blanquear al prójimo como cazar venados, no tiene la disculpa del abandono. Para él hubo escuela, cariños maternales, aceptación social, amor. La vida se le brindó en todas las cosas gratas y amables que invitan a la bondad generosa. Su personalidad dispuso de todas las posibilidades que desembocan en la realización de una existencia útil.

No puede quejarse, pues, ni de los demás hombres ni de la vida. Para él -casi exclusivamente-fueron los colegios bien servidos, los juguetes caros, la solicitud familiar. Si acaso, podría quejarse contra sus propias gentes. Las que le dieron armas desde niño. Las que satisfacieron sus caprichos. Las que confundieron el amor con la tolerancia desmedida. Las que no quisieron o no pudieron atajar sus impulsos descontrolados, su afán de satisfacciones sensuales, sus brotes de pequeño demonio. $Y$ al cabo, cuando convertido en un ente peligroso ante quien habían fracasado la escuela, el calor del hogar, los llamados a la rectificación, en vez de entregarlo a la justicia de los tribunales, para que ella realizara con su dureza lo que no conquistó la persuasión, o en último término para evitarle en la cárcel los desvíos y caídas que propiciaba la libertad, se complicó en su favor y en lugar de infringirle un correctivo, le dió un premio.

Este es el caso doloroso, el aspecto descontrolador de los pistoleros consentidos. No es que ellos sean más dignos de castigo que los criminales vulgares. No es que por su dinero o sus preeminencias, los trabajadores anónimos que nos ganamos la vida con el sudor de nuestras frentes, les envidiemos algo y nos gocemos en verlos perseguidos. Lo que nos impele a la protesta es un sentido íntimo de justicia y un movimiento reflejo del instinto de legítima defensa. En el que cae hoy o cayó ayer bajo las balas frías de un criminal impune, podemos vernos a nosotros mismos, podemos ver al pariente, al amigo, a cualquier vida humana interrumpida estúpidamente.

No pedimos la pena de muerte, ni la tortura, ni la maldición para los pistoleros consentidos. Pedimos, sencillamente, que sean separados del resto de la sociedad, encarcelados con la misma intención defensiva que se enjaula un tigre, una serpiente venenosa, un toro cimarrón. Pedimos que los tribunales de justicia no se excusen de conocer en las causas instruidas a señoritos de familia estimable. Exigimos que cada quien se haga responsable de sus deberes para con la colectividad, que son sagrados, antes de satisfacer las exigencias de la comadrería organizada. Propugnamos por una justa deducción de responsabilidades. Y denunciamos, de una vez, la complicidad de ciertos malos hombres de leyes, que nunca ser acercaron a una cárcel, donde posiblemente hay más de un desgraciado que MERECE REIVINDCACION, y si están listos a invocar como sacrosanto el derecho de la defensa jurídica, siempre que el defendido sea un sujeto con ascendiente, con dinero y con nombre...

Ciertos defensores de oficio de las gentes que pagan, - y que pagan a manos llenas - son indiferentes a la desgracia de los que caen por fatalidad o han sido víctimas de una imperfección de la ley. En estas ocasiones se encogen de hombros. Aquí no recuerdan que el derecho de defensa es sagrado. Aquí no asumen esa pose solemne de caballeros de bien, de cruzados de la justicia, de Quijotes de la verdad, y en última instancia de sacerdotes sacrificados a un culto de compasión, que les caracteriza cuando tratan de justificar a un cliente jugoso.

Los libros aprendidos en la Universidad sirven para asustar a los profanos. Las gentes sencillas se dejan sorprender con suma facilidad por esa jerga pseudo-científica y antihumana que se gastan algunos honorables 
de relumbrón, pero no ocurre lo mismo con los individuos de algún alcance mental, aun cuando éste sea mediocre y limitado. Afortunadamente, o desgraciadamente, nos encontramos en este número. A nosotros jamás nos ha engañado la falsa lógica de ciertos tinterillos con título. Si hemos guardado silencio, ha sido porque el periodista, en nuestro medio, se encuentra a merced de todos los riesgos. Pero ha llegado la hora de hablar con claridad, y así lo hacemos, siquiera sea para que esos señores tengan la convicción de que existen muchos que sincera y lealmente no creen ni en su talento, ni en su honorabilidad, ni en su fama.

Y si, creen, por otra parte, con toda sinceridad y lealtad, que ellos son cómplices directos de la corrupción social y de la delincuencia convertida en deporte.

Si ellos no aconsejaron los chanchullos que ponen fuera de la sanción legal a los criminales reincidentes, éstos se ahorrarían cometer nuevos crímenes; muchas vidas humanas se habrían resguardado; muchos lamparones de escarnio se habría evitado el cuerpo social. Si ellos no aceptaran el dinero maldito que se les ofrece para empañar los hechos, subvertir realidades, esconder la verdad, burlar la justicia, el crimen que natural y lógicamente sigue a la anterior absolución, no se habría perpetrado tan fácilmente.

Con estos instrumentos ciegos del mal, con estos aparatos al servicio del egoísmo, figuran los tribunales de conciencia que no tienen conciencia; los que pagan la defensa con tal que ésta se haga por los medios legales y los medios vedados; los que prestan a dar testimonios falsos o que sencillamente se callan la verdad; los que en una u otra forma han contribuido a que lo blanco sea negro, y lo negro blanco.

Esos defensores del mal; esos compradores de la defensa; esos instrumentos de la mentira que se sienten muy serios en sus tarimas de jurados y tienen la íntima convicción de su farsa; esos testigos que no vieron nada, porque no tienen ojos para el delincuente estimable; esos, y no otros, son los responsables de que los criminales reincidan. Sobre ellos recae la culpa de los asesinatos, los robos, los atropellos que no se habrían registrado si hubieran sido previsores y justos. Ellos soltaron al criminal que había herido a un prójimo, a sabiendas de que era un delincuente peligroso. Ellos probaron legalmente la inocencia de la ferocidad, la ineficiencia del zarpazo, la inocuidad del veneno. Y finalmente dejaron al reo en plena libertad, antes que castigado, premiado por sus actos, autorizado para seguir cometiendo tropelías.

Esas gentes ocupan, el mismo lugar del delincuente. Aún más: tienen una culpa mayor.

¿Cómo castigarían las leyes a quien soltara un tigre en plena población, a sabiendas de que es tigre y que puede causar insospechados destrozos?

Seguramente, ese acto sería castigado como un delito. Contra él se rebelarían no únicamente las autoridades constituidas, sino la población entera.

Pues bien, el amparar a un criminal unánimemente reconocido como tal; conseguirle la libertad por todos los medios posibles y finalmente dejarle en condiciones de dar suelta a sus innatos impulsos ofensivos, estimulados intensamente por la impunidad, es más grave que soltar una boa en la vía pública.

Vea la sociedad salvadoreña cómo está amenazada en la vida de sus miembros, y trate de reaccionar, más que contra el crimen, contra quienes le dan vigencia. 


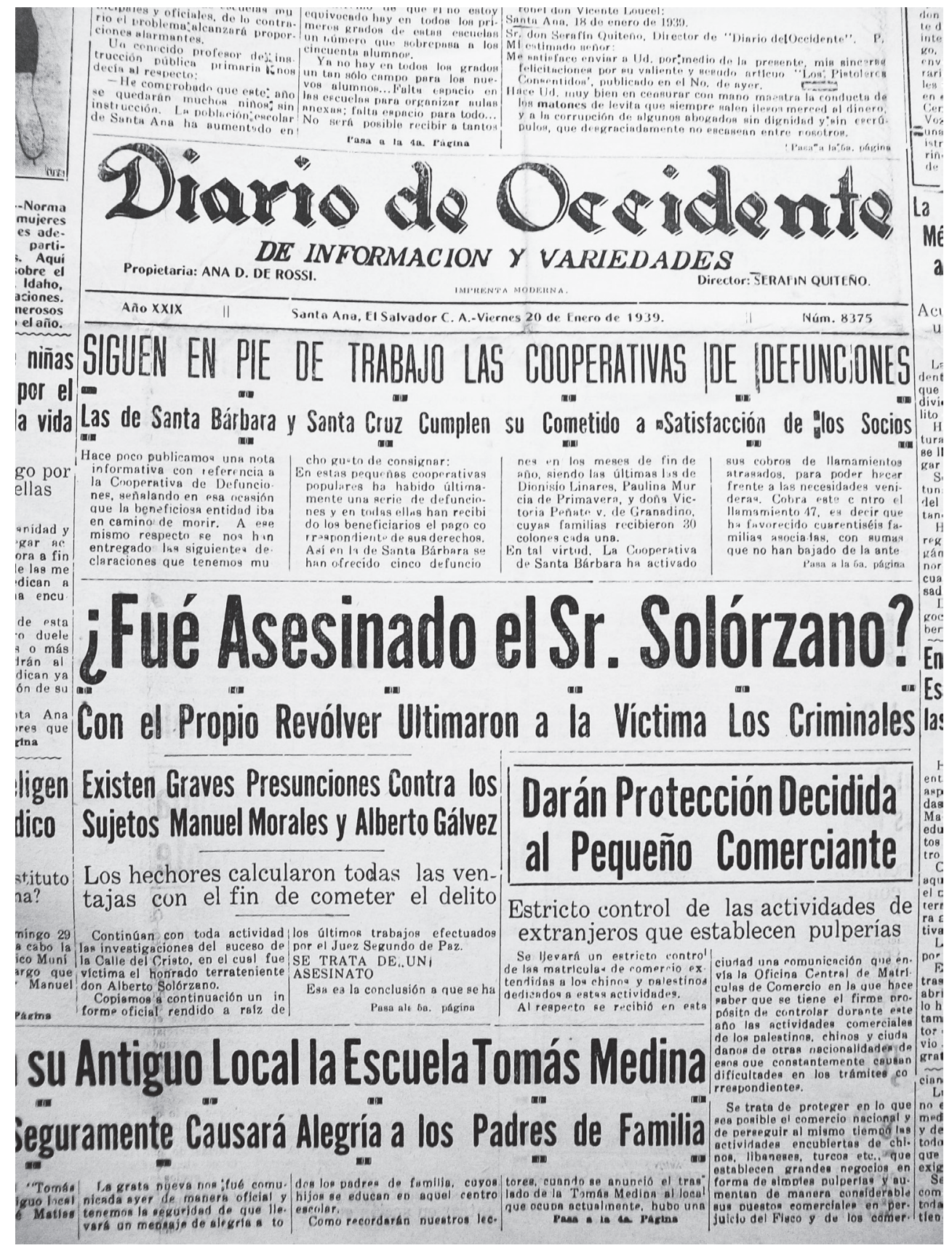




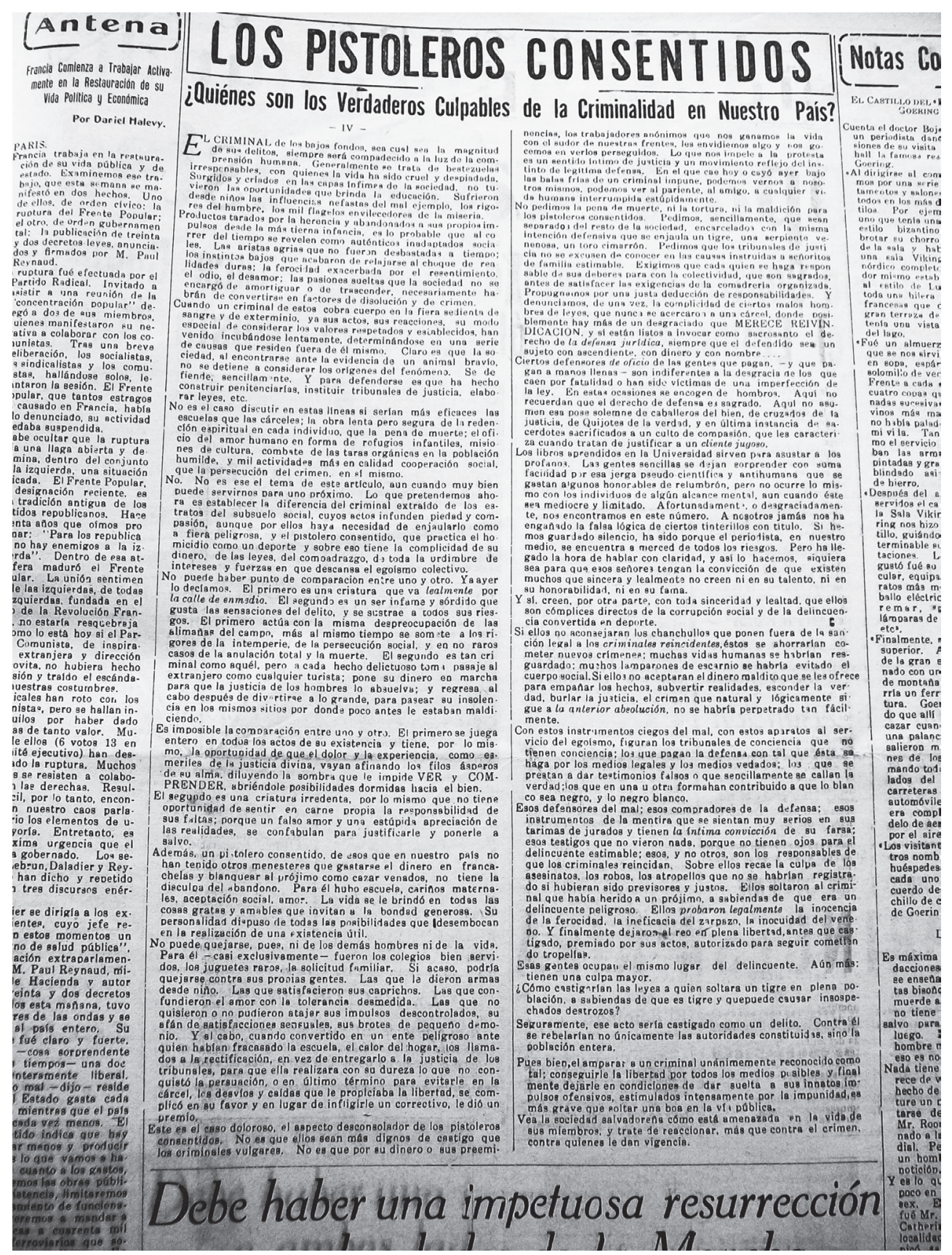

